\title{
Identifying the Old English exponent for the semantic prime LIVE ${ }^{1}$
}

\author{
Raquel Mateo Mendaza \\ University of La Rioja
}

The aim of this article is to identify the Old English exponent for the semantic prime LIVE following the principles of the Natural Semantic Metalanguage theory (Wierzbicka 1996, Goddard \& Wierzbicka 2002, Goddard 2011). The methodology applied in the study is based on previous research in Old English semantic primes. In these terms, a search for those Old English words conveying the meaning of the semantic prime LIVE is made. This search selects the verbs (ge)buan, drobtian, (ge)eardian, (ge)libban, and wunian as candidate words for prime exponent. Then, these verbs are analysed in terms of morphological, textual, semantic, and syntactic criteria. With this purpose, relevant information on these words has been gathered from different lexicographical and textual sources in Old English, such as the Dictionary of Old English, the Dictionary of Old English Corpus, and the lexical database of Old English Nerthus. After the analysis of these verbs, the conclusion is drawn that the Old English verb (ge)libban is selected as prime exponent, as it satisfies the requirements proposed by each criterion.

Keywords: Natural Semantic Metalanguage; Old English; semantic primes

\section{Introduction}

The main aim of the Natural Semantic Metalanguage Research Programme (hereafter NSM; Wierzbicka 1996; Goddard 2002, 2011; Goddard \& Wierzbicka 2002) is to identify a shared core of terms present in all natural languages, by

\footnotetext{
1 This research has been funded by the grant FFI2017-83360P, which is gratefully acknowledged.
}

Raquel Mateo Mendaza, Selim26 (2021): 85-107.

ISSN 1132-631X / ISSN-L 2792-3878 / https://doi.org/10.17811/selim.26.2021.85-107 
means of which complex concepts can be explained in terms of simpler or more intelligible ones. For nearly thirty years, NSM researchers have been investigating different languages and cultures to find and classify the set of words or expressions - semantic primes - that can be considered universal. With this purpose, an inventory of primes has been established for several living languages. A complementary avenue of research is searching a historical language such as Old English (henceforth OE) for semantic primes. Recent studies in OE semantic primes have dealt with the category Actions, Events, Movement, Contact by establishing the OE exponents for DO, HAPPEN, MOVE, and TOUCH (Mateo Mendaza 2013, 2016a, 2016b, 2020). ${ }^{2}$ Along with the search for prime exponents, a methodology has been devised to apply to historical languages in general, with which various candidates for prime have been examined and accurate results from different convergent perspectives have been obtained.

Against this background, the aim of this article is to identify the $\mathrm{OE}$ exponent of the semantic prime LIVE, included within the category Life and Death. The article is organised as follows. Section 2 summarises the main basis of the NSM theory and the progress on the identification of OE exponents that has been made so far. Section 3 makes a descriptive analysis of the semantic prime LIVE within the NSM theory. Then, Section 4 focuses on the selection of candidates for prime exponent among the list of verbs with the meaning 'to live' that can be found in the lexicographical sources. With these data, Section 5 presents the results of the assessment of the candidates as to four different criteria. Finally, the main conclusions and the future lines of research are summarised in Section 6.

\section{The Natural Semantic Metalanguage model and its application to historical languages}

The NSM is a linguistic model that focuses on meaning to understand the basis of a given language. In contrast to other formal models, Anna Wierzbicka developed the idea that all concepts in a language can be explained in a simpler way by means of other more basic concepts. Since 1972, the main aim of the NSM community has been to identify those basic concepts — semantic

\footnotetext{
${ }^{2}$ The primes included in this category have been rearranged and, currently, this category is labelled Actions, Events, Movement. The prime TOUCH is now included within the category Place.
} 
primes - present in all languages, to define their inner meaning and to delimit the contexts in which these words are found cross linguistically. In this seminal study, Wierzbicka proposed an inventory consisting of fourteen semantic primes. Nowadays, the updated list of semantic primes has been enlarged to sixty-five elements divided into different categories, as described in the Natural Semantic Metalanguage Homepage (hereafter NSM Homepage, ${ }^{3}$ see Figure 3). Along with the universal description of the lexicon, semantic primes are also associated with universal syntax. Each prime has a basic configuration minimal frame - established by its basic syntactic requirements. For example, DO asks for an obligatory agent slot and a complement. However, there are other alternative valency options related to each prime that fill out some aspects implied by the predicate (Goddard 2008: 13). In the case of DO, additional arguments may refer to the patient, the instrument, or the comitative case. These valency options are also inherent to the prime and, thus, found crosslinguistically. This can be seen in Table 1 .

Table 1. Minimal frame and valency options for DO (Goddard 2008: 13)

Someone DOES something

Someone DOES something to someone/something

Someone DOES something to someone/something with something

Someone DOES something with someone [minimal frame] [patient] [instrument] [comitative]

Regarding semantic analysis, semantic primes combine with each other in explanations, where complex meanings are decomposed in simpler terms to avoid obscurity and circularity. For some complex concepts further information is needed. With this purpose, the NSM theory introduced the term semantic molecules $[\mathrm{M}]$, defined as language dependent terms that cannot be directly decomposed into primes and that function as conceptual building blocks in the meaning structure of other more complex words (Goddard 2011: 71). Table 2 shows how explications work within the English language and the need for semantic molecules to describe complex concepts.

\footnotetext{
${ }^{3}$ https://intranet.secure.griffith.edu.au/schools-departments/natural-semanticmetalanguage
} 
Table 2. Explanation of head, including an example of a semantic molecule [M] (Goddard 2008: 23)

Head (someone's head)

a. One part of someone's body

b. This part is above all other parts of this someone's body

c. This part is round $[\mathrm{M}]$

To check the universality of this theory as a tool of semantic analysis, the NSM model has been applied to several languages such as Polish, Chinese, Finnish, Italian, Spanish, Cree, Lao, or Arabic, among others. The first studies on these languages were based on the identification of prime exponents crosslinguistically. The advances made on the NSM theory led to new studies based on detailed descriptions of complex concepts by means of explications that analyse the components involved within the meaning of emotions, speech act verbs, motion, or mental states, for instance. This theory has recently been expanded and implemented in related disciplines such as language acquisition, lexicography, and language teaching.

On the side of the application of the NSM to historical languages, semantic studies in the history of some cultural keywords have been carried out by Wierzbicka (2006), while other studies have been conducted that engage in meaning descriptions in Middle English and Old Norse-Icelandic, as well as prime identification in OE. ${ }^{4}$ The latter focus on the OE exponents of the primes included in the categories Substantives, Determiners, Quantifiers (Martín Arista \& Martín de la Rosa 2006) and Descriptors (de la Cruz Cabanillas 2007); on the semantic analysis of compound adpositions (Guarddon Anelo 2009); and on the sematic primes TOUCH, HAPPEN, MOVE, and DO (Mateo Mendaza 2013, 2016a, 2016b, 2020). The studies on TOUCH, HAPPEN, MOVE, and DO have devised a detailed methodology for the identification of semantic prime exponents in historical languages. It comprises the whole process involved in prime identification, from the selection of possible candidates for prime exponent to their assessment as to exponency. In this sense, possible candidates for prime exponent are selected after checking various lexicographical sources, such as historical thesauri and dictionaries. These lexicographical sources confirm that the prime candidate was used during the OE period to convey the

4 Readers are referred to the NSM-approach webpage for further information (https://nsm-approach.net/). 
meaning under analysis. Finally, prime candidates are assessed as to criteria of four types: morphological, textual, semantic, and syntactic.

The selection of these criteria is based on the notion of markedness, as proposed by Croft (1991), as it is closely related to the principle of reductive paraphrase that is central to the NSM theory. In this sense, unmarked concepts in a language would be less complex, more frequent and more iconic than marked ones. Therefore, the former would be used to explain the latter in the same way as semantic primes are used to describe the meaning of complex words.

Bearing this idea in mind, the morphological criterion analyses the inheritance relations of the candidate words by examining the lexical paradigm in which these candidates are included. According to this criterion, primitives of lexical derivation are preferred as they are the words around which the whole derivational paradigm is gathered. Indeed, the productivity of the paradigm is also measured not only in quantitative terms, but also in qualitative ones. That is to say, the different word formation processes that have given rise to the derivational paradigm and the lexical categories of the derivatives will be also seen as conclusive features.

In terms of textual frequency, this criterion counts up the number of types and tokens found for the given candidate within the $\mathrm{OE}$ available texts. A high number of textual types and tokens is associated with the frequency of the candidate. As just said, unmarked concepts are more frequent than marked ones. This relates to the NSM principle that states that complex words can be explained in terms of simpler and more accessible words. If the candidate word repeatedly appears in the corpus, that would mean that it is highly available for the speaker to be used within a language. Thus, that word can be considered a good candidate for semantic prime exponent.

Regarding semantics and syntax, these criteria stipulate that the candidate resembles as much as possible the prototype. In this sense, the exponent should display the meaning of the semantic prime, as established by the NSM theory, as its primary or core meaning. Furthermore, when the exponent is used with this meaning, its complementation patterns would also conform to the ones selected by the semantic prime. At this point, the valency options associated with the semantic prime are also studied, since identifying instances of the exponents within the different syntactic alternations associated with the prime would also determine their suitability as prime exponent.

This said, Table 3 shows the updated inventory of primes proposed by the NSM approach along with the OE exponents identified to date. 
Table 3. Inventory of semantic primes and $\mathrm{OE}$ exponents (in bold)

\begin{tabular}{l|l}
\hline $\begin{array}{l}\text { I-ME=IC, YOU=ĐU, SOMEONE=MAN, } \\
\text { SOMETHING=HWHT } \text { ĐING, } \\
\text { PEOPLE=FOLC/LEODE, BODY=BODIG }\end{array}$ & Substantives \\
\hline KINDS, PARTS & $\begin{array}{l}\text { Relational } \\
\text { substantives }\end{array}$ \\
\hline $\begin{array}{l}\text { THIS=ĐES, THE SAME=ILCA/SELF, } \\
\text { OTHER-ELSE=OĐER }\end{array}$ & Determiners \\
\hline $\begin{array}{l}\text { ONE=AN, TWO=TWEGEN, SOME=SUM, } \\
\text { ALL=EALL, MUCH-MANY=MICEL FELA, } \\
\text { LITTLE-FEW }\end{array}$ & Quantifiers \\
\hline GOOD, BAD, BIG=MICEL, SMALL=LYTEL & Evaluators, descriptors \\
\hline $\begin{array}{l}\text { KNOW, THINK, WANT, DON'T WANT, FEEL, } \\
\text { SEE, HEAR }\end{array}$ & Mental predicates \\
\hline SAY, WORDS, TRUE & Speech \\
\hline $\begin{array}{l}\text { DO=(GE)DON, HAPPEN=(GE)LIMPAN, } \\
\text { MOVE=(GE)STYRIAN }\end{array}$ & $\begin{array}{l}\text { Actions, events, } \\
\text { movement }\end{array}$ \\
\hline $\begin{array}{l}\text { BE (SOMEWHERE), THERE IS, BE } \\
\text { (SOMEONE/SOMETHING), (IS) MINE }\end{array}$ & $\begin{array}{l}\text { Location, existence, } \\
\text { specification, } \\
\text { possession }\end{array}$ \\
\hline LIVE, DIE & Life and death \\
\hline $\begin{array}{l}\text { WHEN -TIME, NOW, BEFORE, AFTER, A LONG } \\
\text { TIME, A SHORT TIME, FOR SOME TIME, } \\
\text { MOMENT }\end{array}$ & Time \\
\hline $\begin{array}{l}\text { WHERE-PLACE, HERE, ABOVE, BELOW, FAR, } \\
\text { NEAR, SIDE, INSIDE, TOUCH=(GE)HRINAN }\end{array}$ & Space \\
\hline $\begin{array}{l}\text { NOT, MAYBE, CAN, BECAUSE, IF, VERY, MORE, } \\
\text { LIKE } \text { AS }\end{array}$ & Logical concepts \\
\hline
\end{tabular}

\section{The semantic prime LIVE}

The inclusion of LIVE into the NSM inventory of primes has not been a straightforward question. The semantic prime LIVE was not considered in the first set of primes proposed by Wierzbicka in 1972. Later on, the inventory was expanded and new primitives were added. Among others, LIVE, along with the 
prime BE (THERE IS/ARE), was included in this new list within the category Existence and Life (Wierzbicka 1996: 124). Subsequent rearrangement of the inventory of primes has led to new categories, and currently LIVE belongs to the category Life and Death, where it appears together with the prime DIE.

It was difficult for the NSM team to define LIVE, as philosophers throughout history have found it hard to define what 'life' is. However, NSM linguists realise that 'life' is an irreducible term that applies to the definition of other complex concepts and, as such, should be considered a semantic prime (Wierzbicka 1996: 86, Goddard \& Peeters 2006: 19) The meaning of the prime LIVE has not been fully described in the NSM theory. Rather, NSM researchers have been focused on establishing arguments required by the prime and the contexts in which its use is considered universal, in contradistinction to language dependent uses.

In general terms, LIVE is described as an existential prime that defines the meaning of being alive as opposed to death. For this reason, it is attributed exclusively to living things, this is to say, to those things that can 'have life', in contrast to non-living things. If we think about living things, the terms bumans, animals, and plants come to our minds. However, it should be recalled, as Wierzbicka (1996: 87) explains, that within the NSM model, living things are defined as 'creatures' that can feel something and do something. In this sense, humans and animals can be considered living things, but plants cannot, as they are unable to feel or do anything.

This explanation for living things is related to the linguistic concept of animacy. LIVE is a predicate prime whose basic configuration calls for an obligatory substantive complement in subject position. However, this substantive complement is restricted to an animate substantive represented by the primitive SOMEONE (in contrast to other predicate primes that also allow SOMETHING as substantive complement in subject position, e.g. SOMEONE/SOMETHING MOVED). In some contexts, SOMEONE can be replaced by specific (PEOPLE) or deictic (I, YOU) substantive complements (Goddard 2008: 71). All things considered, the resulting basic expression or minimal frame for LIVE would be SOMEONE LIVES.

Semantic primes also display specific properties that are inherent to each prime. In the case of LIVE, it is an imperfective verb -in contrast to 'die', which is perfective - and, consequently, it is intrinsically durational (Wierzbicka 2002: 106, Goddard 2008: 72). This means that living is a time dependent activity and as such, it can occur with durative phrases such as FOR A LONG TIME, AT THE SAME TIME, AT THAT TIME, etc. acting as 
temporal adjuncts. Apart from this aspectual property, the manner property is also related to LIVE in the sense that it allows for variation in manner (Goddard 2008: 72). Therefore, the expression with the manner adjunct SOMEONE LIVES LIKE THIS (=IN THIS WAY) is also found cross-linguistically.

There are other optional syntactic configurations associated with LIVE. These configurations are called valency options within the NSM framework. As has been explained above, apart from the basic configuration of each prime its minimal frame - there are other optional arguments that can be used in order to complete some situational aspects expressed by the predicate prime. The combinatorial possibilities found for LIVE are available from the NSM homepage. The labels are assigned according to standard semantic roles.

Table 4. Combinatorial possibilities for LIVE in terms of the NSM grammar along with their semantic roles

\begin{tabular}{ll|}
\hline Someone LIVES for a long time & [time] \\
Many people LIVE in this place & [place] \\
This someone LIVES with someone else & [comitative] \\
It is good if someone LIVES like this & [manner-evaluator] \\
\hline
\end{tabular}

The time and manner valency options are connected to the durational and manner properties inherent to the prime LIVE. In the example provided, the manner frame is extended into a more complex one by a sentence that evaluates the way of living. In Table 4, the sample sentence evaluates this living as something positive by means of the prime GOOD; conversely, the same sentence with the evaluator BAD would also be well-formed. This is an illustrative example of how and to what extent semantic primes can combine with one other to define more complex meanings.

The comitative alternation is also possible universally, since we can talk about sharing life with others. It is important to consider that LIVE WITH is an 'interpersonal' valency. This is so because it is constrained to personal substantives. As stated by Goddard, LIVE is "inherently more 'social' than other primes" (2008: 71) and this valency option is only possible if both the obligatory and the extra personal argument are personal substantives, this is to say, if they imply that someone lives with someone else. The opposite - someone lives with something else- is not accepted.

Finally, the question of location deserves further attention. The semantic prime LIVE can also occur with a locational adjunct. However, it is important to bear in mind that not all the various meanings conveyed by the English word 
live are found cross-linguistically and, therefore, they are not part of the NSM framework. In English, the verb live is polysemic, as it makes reference both to the sense 'to be alive' but also to that of 'to live in a place'. The latter meaning can be understood from two different perspectives. 'Living in a place' can be described in terms of permanent living conditions - fish live in water- or referring to a residential or temporal meaning -I live in Canberra. In terms of the NSM model, the semantic prime LIVE is described as localisable along with other semantic primes such as HAPPEN, MOVE, TOUCH, or BE. However, in contrast to the latter primes, LIVE does not allow for a locus argument (SOMEWHERE). Thus, sentences like SOMEONE LIVES SOMEWHERE, corresponding to the residential or temporal meaning described above, are not relevant for this theory as they are not considered universal. On the other hand, LIVE allows for a domain argument which is expressed with the NSM construction KIND OF PLACE (Goddard 2008). This meaning refers to the example fish live in water, which expresses locational domain and can be found in every natural language resulting in sentences like SOMEONE LIVES IN A KIND OF PLACE. To summarise, only those contexts in which the English word live refers to permanent living conditions are considered universal and, as such, relevant for the NSM studies (Wierzbicka 1996: 126, Goddard \& Wierzbicka 2002: 54, Peeters et al. 2006: 132, Goddard 2008: 79).

In order to enrich and compare the conclusions on different meanings related to LIVE, this question has been addressed in applications of the NSM to languages other than English. In some languages, such as German, Spanish, or Polish, among others, locational meanings are expressed by means of two different words (leben - wohnen, vivir - babitar, żyć - mieszkać, respectively). In these languages, the word selected as prime exponent (the first one in each pair) expresses the universal meaning, whereas a different word (the second one for each pair) is preferred to talk about inhabiting or dwelling in a certain place (a street, town...) (Peeters et al. 2006). Other languages are similar to English and a single word presents both meanings, as in Korean, Amharic (Ethiopia), or Bunuba (Australia) (Goddard 2008). It is important to take into account that, as Goddard points out, within the identification of exponents " $[t]$ he exponent of LIVE need not be the same verb which expresses the meaning 'reside, live in a (particular) place', 'dwell', or 'inhabit"' (2012: 54), as is the case with English. The requirements for prime identification estipulate that the word selected as prime exponent should be the one that, in terms of localisation, gives preference to domain argument, regardless of its secondary temporal meanings, if any. 


\section{Selecting candidates for prime exponent}

The discussion of the semantic-syntactic features of the semantic prime LIVE within the NSM framework must be prior to exponent identification, since the verbs selected as possible candidates should convey the meaning components considered in Section 3.

As pointed out in previous research (Mateo Mendaza 2020: 132), the studies in prime identification are purely synchronic and the suitability of candidates must be gauged within the limits of the $\mathrm{OE}$ period. Following the methodological steps described in Section 2, several lexicographical sources of $\mathrm{OE}$ have been consulted in order to select candidates for prime exponent.

Firstly, we have looked up the Historical Thesaurus of the Oxford English Dictionary (hereafter HTOED, Kay et al. 2009), which provides ten OE verbs under the heading '01.02.00 (vi) Live', namely, beon, gebidan, (ge)blawan, lifes/feores neotan, geseon, wesan, alibban, gelifian, wunian, and (ge)libban. ${ }^{5}$

To contrast these data, the lexical database of OE Nerthus (Martín Arista et al. 2009) has been accessed. This database contains more than 30,000 entries based on the information retrieved from Clark Hall's (1996), Bosworth-Toller's (1973, hereafter Bosworth-Toller), and Sweet's (1973) dictionaries. A search launched for verbs conveying the meaning 'to live' yields eight OE verbs, namely, älibban, cwiclifian, drobtian, (ge)bidan, (ge)buan, (ge)eardian, libban, and wunian.

It is noteworthy that only the verbs (ge)bidan, älibban, (ge)libban, and wunian are found in both sources. In the case of the HTOED, this source does not define the specific meaning of the verbs included within each category. Therefore, it is important to revise in detail the semantics of each candidate in order to decide whether they should be considered part of the subsequent analysis for prime exponent or they should be removed from the list. With this purpose, the meaning of the non-concurrent verbs has been checked against the Dictionary of Old English (hereafter DOE, Healey et al. 2018). This source selects citations from its corpus and gives meaning definitions ordered by hyponymy. As the DOE has only published entries for headwords starting with the letters A-I, the meaning of the rest of the words have been checked against BosworthToller. This search indicates that the verbs presented in Table 5 do not convey the meaning 'to live' in a straightforward way.

\footnotetext{
${ }^{5}$ Note that the HTOED makes no distinction of vowel length.
} 
Table 5. Definitions of some OE verbs found in the DOE (A-I) and Bosworth-Toller

$\begin{array}{ll}\text { wesan: } & \text { 'to be, exist, live' } \\ \text { beon: } & \text { 'to be, exist, happen, become' } \\ \text { (ge)blawan: } & \text { 'to blow, inflate, breath' } \\ \text { geseon: } & \text { 'to see, look, observe' } \\ \text { lifes/feores neotan: } & \text { 'to enjoy life' } \\ \text { neotan: } & \text { 'to enjoy, have the benefit of, make use of }\end{array}$

These definitions suggest that, on the one hand, beon and wesan are purely existential verbs and they do not exactly denote the sense of 'living'. On the other hand, the verbs (ge)blawan and geseon refer to the meaning 'to live' in a figurative sense. As regards lifes/feores neotan, this collocation is frequently found in OE; however, the verb neotan can be used with many other nouns in the genitive, and thus it is not restricted to the term live. Consequently, these verbs have been removed from the list of candidates.

After this revision, the list of candidates is reduced to the verbs alibban, (ge)bidan, (ge)buan, cwiclifian, drobtian, (ge)eardian, (ge)libban, gelifian, and wunian. Nevertheless, this selection of verbs requires further examination. First of all, the verb gelifian is found in lexicographical sources as an alternative spelling of the verb (ge)libban and not as a verb on its own. Thus, these words would be studied together. Besides, the DOE does not provide an entry for cwiclifian, but for its present participle form cwiclifiende. This source evidences that only two occurrences are found for this participle form and, moreover, they are found exclusively in poetry. The same information is provided when cwiclifian is looked up in Bosworth-Toller. Although this dictionary does provide an entry for cwicfilian, only the meaning for its past participle form is presented. With these data, the verb cwiclifian has been removed from the list of candidates.

In the case of (ge)bidan, a first look at this verb suggests that it is directly related to the Present-Day English (hereafter PDE) verb abide, whose meaning is clearly far from the semantic prime under analysis, as explained in Section 3. A search in etymological sources confirms this statement. Orel (2003: 46) relates bidan to the Proto-Germanic form *bidanan and defines its meaning as 'to bide, to abide, to continue, to wait'. Skeat (1993: 38) studies etymology from the $\mathrm{PDE}$ perspective and also associates the PDE verb bide (close to the meaning 'to await, to wait') with the Anglo-Saxon form bidan. On the semantic side, Mitchell claims that "bidan is felt to be a verb of 'rest" (1985: 476) in contrast 
to the dynamic and durational meaning associated with live. Given this evidence, (ge)bidan has not been considered as a candidate for prime exponent.

Regarding a alibban, this verb is a morphological derivative of libban. Although it appears as an independent entry in the different sources that have been consulted, it is important to study this verb in detail. On the one hand, the meanings provided for alibban in the dictionaries ('to be alive, have life; to remain alive (after risk of death), to survive; to spend (one's days), live (one's life)') are included within the meanings proposed for (ge)libban. In this respect, Kastovsky (1992) points out that the prefix $a^{-}$, among other verbal prefixes, shows no change in meaning when attached to a simplex form. Kastovsky (1992: 377) stresses that "in subsequent copies of one and the same text prefixes are often omitted, added or exchanged for other prefixes without any apparent semantic effect. This points to a considerable weakening of the meanings of these prefixes". This effect is considered by Hiltunen (1983: 54) as a lack of expressive content of this kind of prefixes and this reveals their incipient decline within the $\mathrm{OE}$ language. ${ }^{6}$ These points are confirmed by quantitative considerations, since the DOE indicates that alibban shows a remarkable low frequency within the corpus, with only twelve occurrences, including all its inflected forms. For these reasons, we can conclude that alibban should not be part of this investigation as an independent candidate.

To recapitulate, the list of candidates is reduced to five OE verbs, namely, (ge)buan, drobtian, (ge)eardian, (ge)libban, and wunian, which, according to the available sources, display the meaning 'to live'. Of these candidates, (ge)libban is etymologically related (Orel 2003, Kroonen 2013) to the label of the prime LIVE. Ringe \& Taylor (2014: 34) find the etymon in the Proto-Germanic form *libai- *libja- 'live' corresponding to Gothic and Old Norse lifa, OE libban.

\section{Assessing prime candidates from different perspectives}

Once the different candidates for prime exponent are selected, the next step of analysis calls for the study of these verbs under the four criteria described in Section 2, namely the morphological, textual, semantic, and syntactic criteria. This section discusses the results thrown by each criterion and selects the candidate that best fulfils the requirements of the $\mathrm{OE}$ exponent for the semantic prime LIVE.

${ }^{6}$ See Martín Arista (2012a) for a panchronic perspective on the question. 
Regarding morphology, the information on the inheritance relations of each candidate has been retrieved from the lexical database of OE Nerthus. As pointed out above, the morphological criterion considers both the hierarchical position of the candidate word within its paradigm, as well as its productivity, understood as frequency and combinability as base of derivation. In terms of its status, words representing the primitive of the paradigm are preferred as they are the words around which the whole derivational paradigm is gathered. ${ }^{7}$ In this case, only the verb (ge)buan is the primitive word of its lexical paradigm. The rest of candidates - (ge)libban, (ge)eardian, wunian, drobtian - are created by means of zero derivation and they derived directly from the nouns liff, eard, (ge)wuna, and the verb (ge)dreogan, respectively. As regards productivity, the number of derivatives as well as the different word formation processes applied and the category of the resulting derivatives are also relevant for exponent selection. In this line, (ge)buan displays a small paradigm, with only nine derivatives, mainly nouns and adjectives, created by means of prefixation, suffixation and zero derivation. On the other hand, the verb libban belongs to a much larger lexical paradigm comprising sixty derivatives. In contrast to the paradigm of (ge)buan, the paradigm of lif also includes compound words and several nouns, adjectives, verbs and adverbs. It is remarkable in this respect that nine out of the sixty derivatives in this paradigm directly derive from the candidate verb libban instead of deriving from the lexical primitive. This is the case with the derivatives àlibban, belibban 1, eftlibban, lifiende, midlifiend, mislybban, oferlibban, unlifigende, and wellibbende. Therefore, (ge)buan and libban show the same number of derivatives of their own (see Figure 1). The rest of candidates are not as productive as gelibban and gebuan and thus, they do not match the requirements of the morphological criterion.

In terms of textual frequency, each candidate has been ascribed to the different types - unlemmatised forms of the verb under analysis - and tokens -occurrences recorded for each type- found in the Dictionary of Old English Corpus (henceforth DOEC, Healey et al. 2009). This analysis concludes that the verb (ge)libban clearly outnumbers the rest of the candidates, with 218 types and 6,635 tokens, against the figures displayed by the rest of candidates, which do not reach half of its occurrences (wunian: 87 types and 2,462 tokens; (ge)eardian: 99 types and 976 tokens; (ge)buan: 45 types and 296 tokens; drobtian: 22 types

\footnotetext{
7 The relationship between paradigmatic morphology and OE word-formation is discussed in Martín Arista (2012b, 2013).
} 

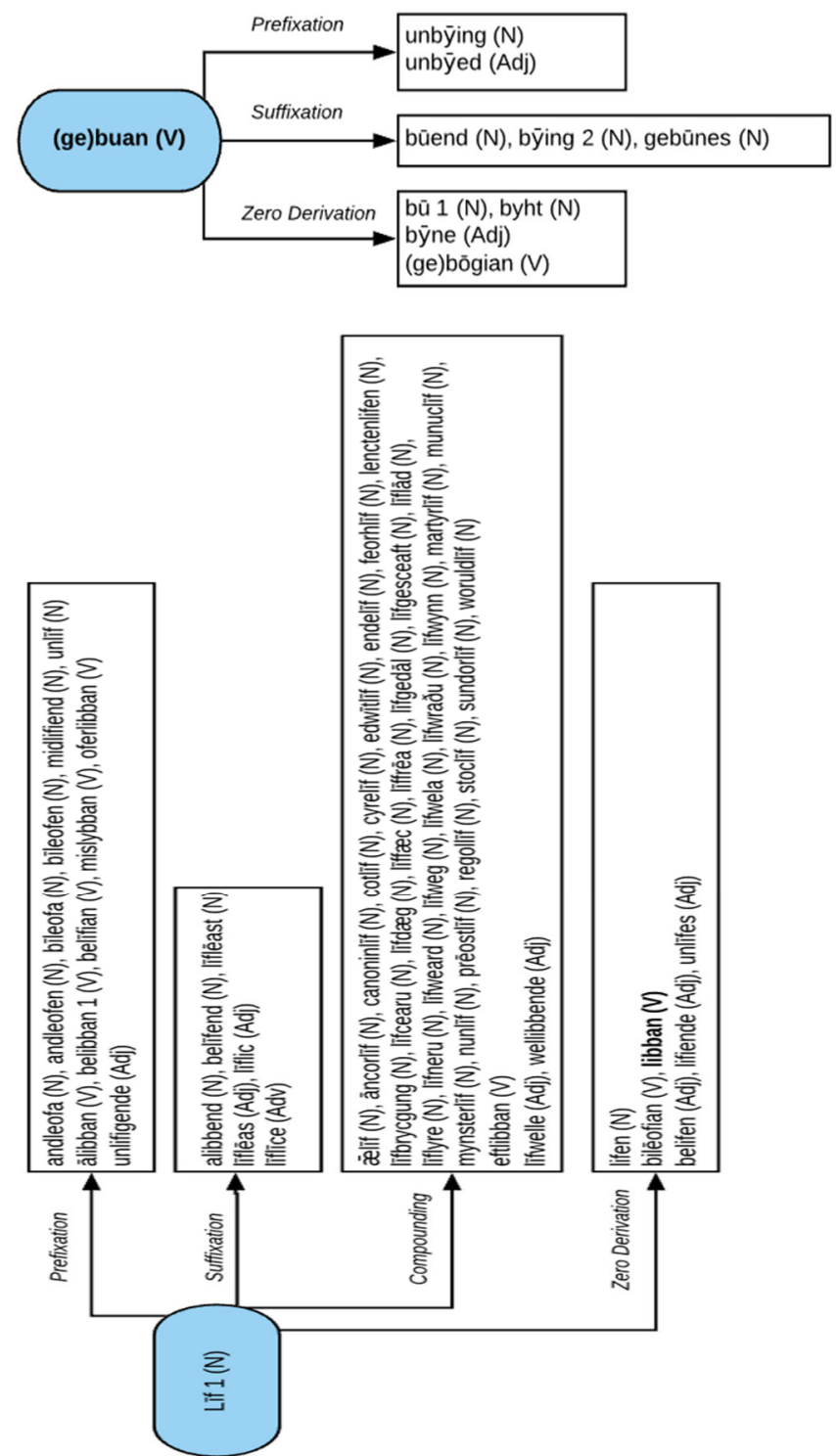

Figure 1. Lexical paradigms of the candidates (ge)buan and (ge)libban (candidate words are displayed in bold) 
and 83 tokens). Hence, the verb (ge)libban is considered the best candidate word for prime exponent in terms of textual frequency.

At this point, it is important to bear in mind that, as explained in previous research (Mateo Mendaza 2016a), the textual criterion can be affected by some linguistic phenomena such as polysemy or homonymy, which may alter the counting of types and tokens. In the case of (ge)libban, homonymy may appear between some verbal and nominal forms such as leofa, libbe, and lybbe, among others. The same happens to the rest of candidates. For example, the forms eardas and eardiende can be attributed to the candidate verb or to the nouns eard and eardiend, respectively; and some homonym words are found within the inflectional forms of (ge)buan and those of the verb (ge)bügan. As regards polysemy, all these candidates have secondary meanings, as detailed below, so that some of their occurrences may not be directly linked to the meaning "to live'. Although the textual criterion is considered the less conclusive one due to the reasons just mentioned, (ge)libban stands out from the rest of candidates. Therefore, this verb is still considered the most suitable candidate word for prime exponent (see Table 6).

Moving on to the semantic and syntactic criteria, the information required to study the different candidates has been gathered primarily from the DOE and completed by consulting Bosworth-Toller.

Dealing with semantics, an outline of the semantic-syntactic features of the semantic prime LIVE and the distinctions found between the English verb live and the NSM approach on this term has already been pointed out in Section 3. Semantically, the selection of an OE exponent for LIVE calls for an intransitive existential verb whose primary meaning refers to live in the sense of 'being alive'. Within the NSM theory, the residential meaning 'to dwell' is not considered universal and, therefore, does not define the semantic prime LIVE. For this reason, candidates presenting the existential meaning of live as their core meaning will be selected as prime exponent.

In this respect, the verbs (ge)eardian and (ge)buan are discarded since they do not conform to the prototype. Both the DOE and Bosworth-Toller refer to (ge)eardian mainly as a residential verb. Only the simplex form eardian is found with the existential meaning in a secondary entry and exclusively in BosworthToller. In the case of (ge)buan, the existential meaning is not considered at all in either of the sources consulted. Bosworth-Toller indicates that the verb wunian also gives preference to the residential meaning, whereas the existential 
Table 6. Types and tokens of (ge)libban found in the DOEC

\section{(GE)LIBBAN}

life (1,641), lifes (1,288), leof (358), leofað (307), leofan (229), libban (163), leofa (148), lyfte (140), leofode (135), libbe (104), lifigende (93), lybban (90), lifde (89), lifigendan (87), leofe (80), libbað (79), lybbað (74), libbende (62), leofast (54), lifgende (53), lybbende (50), lybbe (47), leofap (46), lyfde (42), lifiende (41), lifigendra (38), lyfar (37), leofodon (37), lyfigendan (35), lyfe (33), lifige (30), lifgendra (29), liofað (28), lifdon (27), lifigendum (27), lifian (26), lifiað (24), lyfes (20), lifge (19), lifgan (19), leofest (17), lifiendan (17), lyfode (16), libbendum (16), lifgendan (16), lyfiendan (14), lyfigende (13), libbendra (13), leofeð (13), lifeð (13), lybbendra (12), leofeð (11), libben (11), lifgendum (11), libbon (11), lifgean (10), leofede (10), lifigenda (10), lyfedon (9), lifigan (9), libbap (9), lifiap (9), lyfige (9), leofedon (8), leofe (8), lifode (8), lyfan (8), lybbendum (8), lifiendra (8), lifigendne (7), lifede (7), lifgað (7), lybbon (7), lifiendum (7), lifigenne (7), libbanne (7), lifedon (7), lifia (7), lifie (7), lybbendan (6), lyfdon (6), lybbenne (6), libbendes (6), lifes (6), lyfian (6), lifigeað (5), lifgen (5), leofodan (5), libbøð (5), libbendne (5), libbenne (5), lyfede (5), lifigean (5), lifigen (5), libbendan (5), lyfiað (5), lifiendne (5), lyfigendra (5), lifgeað (4), libbeð (4), liofost (4), lifiendes (4), lifgendne (4), Liofa (4), lifiga (4), lyfigenda (4), lyfge (4), lybbendre (3), libbep (3), lyfedan (3), lybben (3), lybbanne (3), lifgiað (3), Lybbendes (3), lifgab (3), libben (3), lyftum (3), lyfigendes (3), lyfgyndra (3), lybbynde (3), lifep (3), lyfdest (2), lifigendon (2), leofdon (2), lyfgendum (2), lifden (2), lifgenne (2), libbad (2), lyfod (2), liofast (2), libbendu (2), lifigað (2), lifigiend (2), libb (2), leofde (2), libbendre (2), lifgenda (2), lyfgean (2), lifgeap (2), lyfgendan (2), lifiendre (2), lyfed (2), lifias (2), lifigiende (2), lifen (2), leofad (2), lybbyndra (2), leofo (2), lifed (2), libbenda (2), leofod (2), lifiendra (2), lifap (2), lybbap (2), lyfigan (1), lyfiendes (1), lyfodon (1), lybbae (1), lifigenden (1), leofoden (1), lybbenda (1), lyfigeanne (1), lifigendre (1), lyfgan (1), leofen (1), lyfie (1), libbinde (1), lifien (1), lyfon (1), lifo (1), lifast (1), lyfiendum (1), lyfiende (1), lifigiendra (1), lybb (1), lyfeð (1), lifgiap (1), leofedan (1), leofep (1), lyfen (1), lyfene (1), life (1), lybben (1), lifianne (1), lifienne (1), leofge (1), lyfenne (1), lyfigean (1), liofeð (1), liofer (1), lifgendre (1), liofan (1), lybbendne (1), leofede (1), lyfigenden (1), lyfigenne (1), lifigendes (1), lyfiendne (1), lifep (1), lifd (1), lyfigynde (1), lifigenda (1), lyfgyndan (1), libbynde (1), lyfigyndne (1), lyfygyndra (1), liofep (1), lifiendan (1), lifiendee (1), liofed (1), lifgendra (1), liofap (1), lybbede (1), libbeb (1), leofgife (1), leofest (1), lybbene (1), lyfigendre (1)

\begin{tabular}{r|r|r}
\hline & TYPES & 218 \\
\hline & TOKENS & 6,635 \\
\hline
\end{tabular}


one is found as a secondary meaning of this highly polysemic verb. As for drobtian, whereas Bosworth-Toller refers to a more figurative meaning of live, the existential meaning appears within the DOE definition along with the residential one. Finally, the verb (ge)libban, both in its simplex and complex form, is defined with the prototypical sense 'to be alive, have life'. Therefore, both drobtian and (ge)libban display the core meaning required by the NSM theory and, thus, they are the most suitable candidates for prime exponent in terms of semantics.

Syntactically speaking, the basic configuration of the prime LIVE opens an obligatory substantive subject slot which must be essentially animate (SOMEONE LIVES). As previously explained, the prime LIVE entails the aspectual property of implying duration (FOR SOME TIME), as well as implying variation in manner (LIKE THIS). For those verbs conveying the meaning at stake, that is, drobtian and (ge)libban, the syntax is examined in terms of the information given by the dictionaries.

As expected by the NSM theory requirements, both verbs open for a substantive subject slot, but its animacy is not described in the sources consulted. The aspectual property of duration and variation in manner is explicitly associated with (ge)libban and drobtian. The entry of libban defines duration as 'to continue in life, be alive for a longer or shorter time, have one's life prolonged', and manner as 'to pass life in a specified fashion, indicated by an adv., adverbial phrase, or adj. or complementary subst.' (Bosworth-Toller). Similarly, drobtian refers to 'to live in an indefinite length of time/ to live a stated length of time', and also allows for variation in manner: 'to live in a certain state or condition, to conduct one's life/ to live in a certain manner, to conduct one's life' (DOE). Therefore, both (ge)libban and drobtian concur with the syntactic patterns described by the NSM theory for the semantic prime LIVE. The semantic and syntactic information found for these two verbs is summarised in Table 7.

Given the results obtained from the application of the four criteria for prime exponency, it can be stated that only the verb (ge) libban fulfils the requirements proposed in terms of morphology, frequency, semantics, and syntax and, therefore, it should be considered the OE exponent of LIVE.

It remains to look for evidence of the exponent word with the valency options associated with the prime under investigation. As described in Section 3 , LIVE is connected to the temporal, locational, comitative, and mannerevaluator configurations. It must be borne in mind that the locational 
alternation is only referred to a domain argument (KIND OF PLACE), since the simpler locus expression LIVE SOMEWHERE is not considered universal.

Table 7. Semantic information of drobtian and (ge)libban retrieved from the DOE and Bosworth-Toller

\begin{tabular}{|c|c|c|}
\hline Entry & Meaning in the DOE $(\mathrm{A}-\mathrm{I})$ & $\begin{array}{l}\text { Meaning in } \\
\text { Bosworth-Toller }\end{array}$ \\
\hline Drobtian & $\begin{array}{l}\text { 1. To live, dwell } \\
\text { 1a. in collocation with other verbs } \\
\text { similar in meaning (eardian, libban) } \\
\text { 1b. to live in an indefinite length of } \\
\text { time } \\
\text { 1c. to live a stated length of time } \\
\text { 1d. lif drobtnian / drobtian lif 'to live } \\
\text { a/one's life' } \\
\text { 2. To live, dwell in a place } \\
\text { 2ai. transferred: to dwell in a person as } \\
\quad \text { in a place } \\
\text { 2aii. figuratively: to dwell in one's heart } \\
\text { 2b. to live under } \\
\text { 2c. to live with } \\
\text { To live in a certain state or condition, to } \\
\text { conduct one's life } \\
\text { 4. To live in a certain manner, to conduct } \\
\text { one's life } \\
\text { 5. To live according to a rule, a teaching a } \\
\text { will or purpose } \\
\text { 6. To engage in, spend life in }\end{array}$ & $\begin{array}{l}\text { I. To converse, } \\
\text { dwell or keep } \\
\text { company with, } \\
\text { pass life, live }\end{array}$ \\
\hline
\end{tabular}

${ }^{8}$ For Bosworth-Toller, the information provided by the main volume and the supplement is summarised in a single entry. 


\begin{tabular}{|c|c|}
\hline Entry & Meaning in Bosworth-Toller \\
\hline Libban & $\begin{array}{l}\text { To live } \\
\text { I. To be alive, have life } \\
\text { a. To remain alive after risk of death } \\
\text { b. fig. Of things } \\
\text { II. To supply oneself with food, feed, subsist (lit. or fig.) } \\
\text { III. To procure oneself the means of subsistence } \\
\text { IV. To pass life in a specified fashion } \\
\text { with regard to conduct } \\
\text { with regard to personal conditions } \\
\text { with adv. or adv. phrase } \\
\text { with adj. or compl. sbst. } \\
\text { with regard to the rule or principle } \\
\text { with cognate object } \\
\text { VI. To continue in life, be alive for a longer or shorter time, have } \\
\text { one's life prolonged; } \\
\text { said of Deity and spirits } \\
\text { VII. To continue in the memory of men } \\
\text { VIII. To make one's abode, reside }\end{array}$ \\
\hline Gelibban & $\begin{array}{l}\text { To live } \\
\text { I. To be alive } \\
\text { III. To escape spiritual death } \\
\text { IV. trans. 1. To have as part of one's life, to experience } \\
\text { 2. To get by living, to live to do }\end{array}$ \\
\hline
\end{tabular}

A search in the DOEC provides examples of (ge)libban within all these configurations, as exemplified below:

(1) a. Temporal [Bede 3060600 (19.244.11)]

Hwat se Exelhun per nebstan neabte forðferde; \& Ecgberbt hine pere aðle getrumade, \& micle tide after pon lifde \& biscophade onfeng, \& pone had mid efenweordum dedum fretwade.

'Well then Æthelhun died next night; and Ecgberht recovered from the illness, and lived long after this and became a bishop and adorned his office with corresponding conduct.' (Miller 1959: 245) 
b. Locational

[ÆCHom I, 28006000 (415.143)]

To eorðan heo bið astreht purb byre scylda oncnawennysse. ponne se lichama pe beo on leofode to duste bið formolsnod.

'To earth it shall be prostrated by a knowledge of its sins, when the body in which it lived shall be rotted to dust.' (Thorpe 1844: 411)

c. Comitative

[ÆCHom I, 9009200 (255.189)]

Seofon gear beo lyfode mid bire were \& syððan beo wes wuniende on wuduwan hade: or feower \& bundeabtatig geara.

'Seven years she had lived with her husband, and was afterwards continuing in widowhood eighty-four years.' (Thorpe 1844: 147)

\section{d. Manner}

[ÆCHom I, 6003600 (227.91)]

Gif ge willað efter menniscum gesceade lybban, ponne sind ge gastlice ymbsnidene;

'If ye will live according to human reason, then are ye spiritually circumcised;' (Thorpe 1844: 372)

These instances confirm that the uses of (ge)libban coincide with those proposed by the NSM theory for the semantic prime LIVE. Consequently, the results provided by (ge)libban in terms of the different criteria under analysis, as well as the valency options associated with this verb, lead us to the conclusion that the verb (ge)libban should be considered the $\mathrm{OE}$ exponent for the semantic prime LIVE.

\section{Concluding remarks}

This research continues the research line opened on the study of OE semantic primes by identifying the OE exponent for the semantic prime LIVE. In this sense, a list of candidate verbs conveying the meaning 'to live' has been analysed and the conclusion drawn from this analysis is that the OE verb (ge)libban is selected as prime exponent.

The methodology applied in this study is based on previous research on semantic primes identification in historical languages and it relies on morphological, textual, semantic, and syntactic data to reach solid conclusions. 
Apart from the analysis of candidates from these four perspectives, the gathering of evidence for the standard uses of the verb (ge)libban with the syntactic complementation patterns - valency options - associated with the prime has been instrumental when assessing the accuracy of the initial proposal for prime exponent.

After establishing (ge)libban as the OE exponent of LIVE, further research calls for the identification of the exponent of DIE to complete the category Life and Death, thus enlarging the inventory of primes in OE. These advances are likely to lead to a refinement of the methodology proposed for the identification of semantic primes in historical languages.

\section{References}

Bosworth, J. \& T. N. Toller 1973 [1898]: An Anglo-Saxon Dictionary. Oxford, Oxford University Press. http://www.bosworthtoller.com

Croft, W. 1991: Syntactic Categories and Grammatical Relations. Chicago, University of Chicago Press.

de la Cruz Cabanillas, I. 2007: Semantic Primes in Old English: A Preliminary Study of Descriptors. SELIM 14: 37-58.

Goddard, C. 2002: The Search for the Shared Semantic Core of All Languages. In C. Goddard \& A. Wierzbicka eds. Meaning and Universal Grammar. Theory and Empirical Findings. Vol. I. Amsterdam, John Benjamins: 5-40.

Goddard, C. ed. 2008: Cross-Linguistics Semantics. Amsterdam \& Philadelphia, John Benjamins.

Goddard, C. 2011: Semantic Analysis: A Practical Introduction. New York, Oxford University Press.

Goddard, C. 2012: Semantic Primes, Semantic Molecules, Semantic Templates: Key Concepts in the NSM Approach to Lexical Typology. Linguistics 50.3: 711-743.

Goddard, C. \& B. Peeters 2006: The Natural Semantic Metalanguage (NSM) Approach: An Overview with Reference to the Most Important Romance languages. In B. Peeters ed. Semantic Primes and Universal Grammar: Empirical Evidence from the Romance Languages. Amsterdam, John Benjamins: 13-38.

Goddard, C. \& A. Wierzbicka 2002: Semantic Primes and Universal Grammar. In C. Goddard \& A. Wierzbicka eds. Meaning and Universal Grammar. Theory and Empirical Findings. Vol. I. Amsterdam, John Benjamins: 41-85.

Guarddon Anelo, M. C. 2009: Un Análisis de las Propiedades Combinatorias de los Primitivos Semánticos a través de las Adposiciones Complejas en Inglés Antiguo. Revista Española de Lingüistica 39.2: 93-122. 
Hall, J. R. C. 1996: A Concise Anglo-Saxon Dictionary. Toronto, Toronto University Press.

Healey diPaolo, A. ed. with John Price Wilkin \& Xin Xiang 2009: The Dictionary of Old English Web Corpus. Toronto. Dictionary of Old English Project. http://www.doe. utoronto.ca/pub/webcorpus.htm

Healey diPaolo, A., A. Cameron, A. Crandell Amos et al. eds. 2018: Dictionary of Old English: A to Gonline. Toronto, Dictionary of Old English Project.

Hiltunen, R. 1983: The Decline of the Prefixes and the Beginnings of the English Phrasal Verb. Turku, Turun Yliopisto.

Kastovsky, D. 1992: Semantics and Vocabulary. In R. Hogg ed. The Cambridge History of the English Language. Vol. I: The Beginnings to 1066. Cambridge, Cambridge University Press: 290-408.

Kay, C., J. Roberts, M. Samuels \& I. Wotherspoon 2009: The Historical Thesaurus of the Oxford English Dictionary. University of Glasgow, Oxford University Press.

Kroonen, G. 2013: Etymological Dictionary of Proto-Germanic. Leiden, Brill.

Martín Arista, J. 2012a: The Old English Prefix Ge-: A Panchronic Reappraisal. Australian Journal of Linguistics 32.4: 411-433.

Martín Arista, J. 2012b: Lexical Database, Derivational Map and 3D Representation. RESLA - Revista Española de Lingüística Aplicada (Extra 1): 119-144.

Martín Arista, J. 2013: Recursivity, Derivational Depth and the Search for Old English Lexical Primes. Studia Neopbilologica 85.1: 1-21.

Martín Arista, J. ed., L. García Fernández, M. Lacalle Palacios, A. E. Ojanguren López, \& E. Ruiz Narbona 2009: Nerthus: An Online Lexical Database of Old English. http://www.nerthusproject.com

Martín Arista, J. \& M. V. Martín de la Rosa 2006: Old English Semantic Primes: Substantives, Determiners and Quantifiers. ATLANTIS 28.2: 9-28.

Mateo Mendaza, R. 2013: The Old English Exponent for the Semantic Prime TOUCH. Descriptive and Methodological Questions. Australian Journal of Linguistics 33.4: 449-466.

Mateo Mendaza, R. 2016a: The Search for Old English Semantic Primes: The Case of HAPPEN. Nordic Journal of English Studies 15.1: 71-99.

Mateo Mendaza, R. 2016b: The Old English Exponent for the Semantic Prime MOVE. Australian Journal of Linguistics 36.4: 542-555.

Mateo Mendaza, R. 2020: Semantic Primes in Historical Languages. The Identification of the Old English Exponent for DO. Journal of English Studies 18: 125-152. https://doi.org/10.18172/jes.4467

Miller, T. 1959: Bede's Ecclesiastical History of the English People. Part I, 2. London \& New York \& Toronto, Oxford University Press.

Mitchell, B. 1985: Old English Syntax. Vol. I. Oxford, Oxford University Press.

Orel, V. 2003: A Handbook of Germanic Etymology. Leiden, Brill. 
Peeters, B., M.-O. Junker, P. Farrel, P. Perini-Santos \& B. Maher 2006: NSM Exponents and Universal Grammar in Romance: Speech; Actions, Events and Movement; Existence and Possession; Life and Death. In B. Peeters ed. Semantic Primes and Universal Grammar: Empirical Evidence from the Romance Languages. Amsterdam, John Benjamins: 111-136.

Ringe, D. \& A. Taylor 2014: The Development of Old English. Oxford, Oxford University Press.

Skeat, W. 1993: The Concise Dictionary of English Etymology. Great Britain, Wordsworth Edition Ltd.

Sweet, H. 1973 [1897]: The Student's Dictionary of Anglo-Saxon. New York \& London, The MacMillan Company.

Thorpe, B. 1844: The Homilies of the Anglo-Saxon Church. London, printed for the Ælfric Society.

Wierzbicka, A. 1996: Semantics. Primes and Universals. Oxford, Oxford University Press. Wierzbicka. A. 2002: Semantic Primes and Universal Grammar in Polish. In C. Goddard \& A. Wierzbicka eds. Meaning and Universal Grammar. Theory and Empirical Findings. Vol. II. Amsterdam, John Benjamins: 65-144.

Wierzbicka, A. 2006: English: Meaning and Culture. New York, Oxford University Press.

\author{
Author's address \\ Departamento de Filologías Modernas \\ Universidad de La Rioja \\ Edificio de Filologías \\ C/ San José de Calasanz, 33 \\ 26004 Logroño, La Rioja (España) \\ e-mail: raquel.mateo@unirioja.es
}

received: 10 February 2021 revised version accepted: 10 March 2021 